\title{
Competitive ranking of six major tea-related research organiza- tions through bibliometric analysis of publications and patents
}

\author{
Huimin Zhao ${ }^{1}$, Jingjing Wang ${ }^{1}$, Xiaowei Yang ${ }^{1, *}$, Xingping Xiong ${ }^{2, *}$ \\ 1 Agricultural Information Institute of CAAS, Chinese Academy of Agricultural Sciences, No.12 Zhongguan- \\ cun South St., Beijing, 100081, P.R.China; zhaohuimin@caas.cn(H.Z.); wangjingjing@caas.cn(J.W.); yangxiao- \\ wei@caas.cn (X.Y.); \\ 2 Tea Research Institute, Chinese Academy of Agricultural Sciences, 9 Meiling South Road, Hangzhou, \\ Zhejiang, 310008, P.R.China; trixxp@tricaas.com; \\ * Correspondence: yangxiaowei@caas.cn (X.Y.); trixxp@tricaas.com (X.X.)
}

\begin{abstract}
Technological advances in tea production are critical to meet global demands for tea consumption. To illuminate differences in the scientific and commercial relevance of research programs between major tea-related research organizations around the world, we conducted a bibliometric analysis comparing the scientific outputs, including peer-reviewed publications and patents, of six major research organizations published between January 01, 2008 and July 11, 2020. For this competitive ranking analysis, we examined a number of papers, research topics, academic influence, capacity for development, capacity for collaboration, and capacity for technological innovation. Among the six research organizations, Anhui Agricultural University (in China) had the most publications, while the Chinese Academy of Agricultural Sciences, Tea Research Institute showed a higher capacity for development. The Council for Scientific and Industrial Research (in India) and the University of Shizuoka (Japan) both showed high academic influence, while the University of Shizuoka, Tea Research Association Tocklai and National Agriculture and Food Research Organization (Japan) showed a high capacity for collaboration. The Chinese Academy of Agricultural Sciences, Tea Research Institute applied for the most patents, while the Council for Scientific and Industrial Research applied for the most international patents.
\end{abstract}

Keywords: tea; competitiveness analysis; bibliometrics

\section{Introduction}

Tea serves as the national drink of China and represents a long-standing component of Chinese history and culture. With technological advances in production, the tea industry is increasingly shifting from traditional to modern industrial methods ${ }^{[1]}$. Continual technical advances in the tea industry are essential for ensuring the competitiveness of the Chinese tea industry in the international market. To illustrate scientific and technological differences between Chinese and international tea research organizations, this study uses bibliometrics as a theoretical basis for determining competitiveness and to provide objective data analysis of the research outputs of major domestic and international tea research organizations.

Research outputs, mainly in the form of peer-reviewed papers, patents, scientific reports, standards, etc. are important criteria for assessing the level of scientific and technological innovations of organizations. Papers represent a summary of the results of theoretical and applied research conducted by investigators across a range of tea-related disciplines ${ }^{[2]}$. Patent documents record the contents of an invention or technological creation, and include not only technical information, but also regional, legal, and economic information. These data are both commonly used as major indicators of the competitiveness of a researcher or research organization.

Bibliometric analysis examines the external characteristics of literature, such as the overarching research topic, and uses statistical methods to study the distribution (e.g., 
availability of a paper among tea researchers), quantitative metrics (e.g., how many downloads and citations), and trends in published literature (annual popularity of a research topic), which are quantitative, objectively determined, and therefore easy to compare. Bibliometric methods have been adopted worldwide for analysis of competitiveness among academic institutions, such as the U.S. News 2019 Best Global Universities Rankings ${ }^{[3]}$, Shanghai Ranking's Global Ranking of Academic Subjects ${ }^{[4]}$, and annual publications evaluating academic competitiveness by Wuhan University ${ }^{[5,6]}$, among others.

This latter method has been used by several scholars to conduct analyses of competitiveness ${ }^{[7,8]}$. Common metrics (as per Web of Science) include Publications, Average publications per item, Sum of Times Cited, and Average citations per item, as well as h-in-

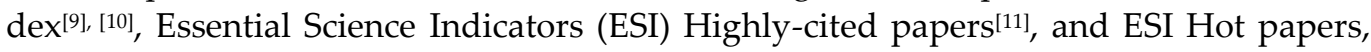
which are all currently recognized as important parameters for analysis of institutional productivity $^{2,[12-14]}$.

In addition to commonly used indicators, researchers have also introduced other indicators to evaluate institutional competitiveness. Liu and colleagues ${ }^{[15]}$ introduced the industry share, i.e., the percentage of papers in a given research area, as an index to reflect an institution's rank in a given research area. In other institutional analyses, Solanki ${ }^{[16]}$ used international collaborative papers (ICP), highly cited papers (HiCP), g-index, hg-index, p-index; Kim et al. ${ }^{[17]}$ used Q1 (index level of paper quality) and Q2 (strength of international collaboration). Similarly, Ruiz-Coronel[18] and Zhong ${ }^{[19]}$ both make use of international cooperation and self-defined High-quality papers to analyze the international status of Chinese research institutions. Gundes ${ }^{[20]}$ and coworkers measured organization productivity through first author papers and collaborative papers. For patent data, Trappey ${ }^{[21]}$ introduced a customized metric of patent quality to compare institutions, while He and Zhao ${ }^{[22]}$ created a Patent Roadmap to compare key technological developments between two institutions. In addition, Liu $^{[23]}$ constructed an indexing system and method of evaluation that combines peer review and Scientometrics. Bibliometric analysis of documents produced by an institution can thus enable a comprehensive understanding of its research quality and productivity, an overview of the current research field, and developing trends among their domestic and international counterparts. This understanding provides a well-informed basis for institution leaders to grasp their status in the research field and subsequently formulate future development strategies ${ }^{[24]}$.

\section{Data and methodology}

The principles selected for comparison among the research organization sample set include: high-impact paper output, research goals, and comparable scale of personnel, and capacity for national or international representation of tea research. The organizations selected for comparison were therefore determined through a combination of quantitative and qualitative methods. To rank the most productive organizations, we searched the SCIE (Science Citation Index-Expanded) database for papers in the field of tea research, with research topics that included tea germplasm, tea plant genetics and breeding, tea cultivation, tea plant physiology and nutrition, tea plant protection, flavor chemistry of tea, tea processing, tea comprehensive processing, tea quality and risk assessment, and the effects of tea on health. Based on the history of tea development, different research organizations, including universities and national research institutions, as independent legal entities, were selected from Japan, India, and China for comparison. The final comparison group of organizations included: Tea Research Institute of the Chinese Academy of Agricultural Sciences (CAAS); Anhui Agricultural University in China (Anhui); University of Shizuoka in Japan (Shizuoka); National Agriculture and Food Research Organization (NARO); Tea Research Association Tocklai in India (Tocklai); Council of Scientific and Industrial Research in India (CSIRI).

The data were obtained from papers that we retrieved from the Web of Science (SCIE and SSCI (Social Sciences Citation Index) databases) with publication dates between Jan 01, 2008 and Jul 11, 2020. Patents were current in the Derwent Innovation and PatSnap 
databases as of July 11, 2020, and were retrieved using search codes that combined each organization name and "tea or camellia*". Derwent Data Analyzer was used to clean and analyze the data. Since the retrieval strategy was developed to accommodate potentially conflicting search parameters that are systematic and comprehensive (most possible hits) but also highly accurate and relevant to tea research (fewer but more relevant hits), there may be omissions or some patents which were not directly related to tea in the retrieval results. After manual curation, we found a total of 1551 papers in SCI-E and 1332 patents from 916 patent families in Derwent Innovation during this period. For data processing and analysis, we used a variety of analytical tools in the Web of Science portal, as well as the Derwent Data Analyzer 10.0, and Microsoft Excel 2016.

The method of Wuhan University ${ }^{[6]}$ (2015) was adopted for comparative analyses, which incorporates four main indicators of institutional capacity for scientific research including: scientific research productivity, scientific research influence, scientific innovation, and network influence. The secondary indicators include the number of papers published, number of citations, ESI Highly-cited papers, disciplines entering the ESI subject ranking, number of ESI Hot papers, number of patents, and Internet influence ranking at home and abroad.

For this study, we made minor modifications, including the addition of two primary indicators (collaborative ability and capacity for development) and removal of network influence, for a total five main indicators. Among secondary indicators, internet influence was replaced with several other metrics, resulting in a total of 29 secondary indicators (Table 1, Table 2, Fig. 2).

Scientific output, which should reflect an organization's academic contributions, was measured by the number papers published by an organization, number of papers with core authors (first and corresponding authors) housed at the institution, and the distribution (proportions) of an institute's published research topics.

Academic influence was measured by citations, including the sum of times cited, average citations per item, the percentage of non-self-citations, and the percentage of cited papers. Citation numbers can serve as indicators of an organization's influence in a given field, with the higher numbers for related citations indicating greater attention that organization attracts within a field, and consequently, the stronger the academic influence of that organization.

$$
\begin{gathered}
\text { average citations per item }=\frac{\text { sum of times cited }}{\text { number of papers }} \\
\text { percentage of non }- \text { self citations }=\frac{\text { sum of non }- \text { self times citated }}{\text { sum of times cited }}
\end{gathered}
$$

The capacity for development was measured by output efficiency, h-index, average percentage of High-quality papers. High-quality papers in this study include High-quality journal papers, Highly-cited papers, and Hot papers. High-quality journal papers refer to papers published in High-quality journals. Here, High-quality journals are defined as those journals that fall within Quartile 1 (Q1) of the Journal Impact Factor (JIF), i.e., with an average JIF percentile of $90 \%-100 \%$, in the 2017 Journal Citation Reports ${ }^{[25]}$. Highlycited papers refer to papers that exceed the citation baseline of papers in a specific data set, which is the number of total papers produced by all six organizations in this study. The citation baseline of Highly-cited papers is calculated as follows. We used the integer 15 , by rounding up from 14.53, as the baseline number of citations for Highly-cited papers. Highly - cited paper citation baseline $=\frac{\text { sum of times cited of Highly }- \text { cited papers }}{\text { total number of papers }}$

$$
=\frac{22522}{1551}=14.53
$$

Hot papers refer to papers among this dataset (i.e., all papers produced by these organizations from Jan 2017 through July 2020) that exceeded the citation baseline just within the past three years. The citation baseline of Hot papers is calculated as follows. We used the integer 8 , by rounding up from 7.35, as the baseline number of Hot paper citation. 


$$
\text { hot paper citation baseline }=\frac{\text { sum of times cited of hot papers }}{\text { total number of papers }}=\frac{5814}{791}=7.35
$$

Therefore, the papers with number of citations greater than or equal to 15 are Highlycited papers, while the papers published in 2017-2020 with citations greater than or equal to 8 are Hot papers. The percentage of High-quality journal papers and average percentage of High-quality papers was calculated as follows (note: the same formula was used for average percentages of Highly-cited papers and Hot papers):

$$
\begin{aligned}
& \text { percentage of High - quality journal papers } \\
& =\frac{\text { High }- \text { quality journal papers }}{\text { total number of papers of the organization }}
\end{aligned}
$$

average percentage of High - quality papers

$$
\begin{aligned}
& =(\text { percentage of High }- \text { quality journal papers } \\
& + \text { percentage of Highly cited papers }+ \text { percentage of Hot papers }) / 3
\end{aligned}
$$

Output efficiency is defined as the ratio of the number of papers to the number of employees, employees being authors who have published papers in the corresponding organization, and thus represents the average number of papers per author.

Collaborative ability was measured by the number of collaborative papers, percentage of papers with collaborating authors, number of collaborative papers among core author papers, contribution of collaborative papers (i.e., the percentage of High-quality journal papers, Highly-cited papers, and Hot papers), percentage of collaborative paper in High-qulity papers, ratio of international High-quality collaborative paper to domestic. The percentage of High-quality journal collaborative papers was calculated as follows (note: the same formula was used to calculate the percentages of Highly-cited collaborative papers and Hot collaborative papers):

$$
\begin{aligned}
& \text { percentage of High - quality journal collaborative papers } \\
& =\frac{\text { High-quality journal collaborative papers }}{\text { total number of collaborative papers }}
\end{aligned}
$$

The ratio of international High-quality collaborative paper to domestic was calculated as follows:

$$
\begin{aligned}
& \text { Ratio of international High - quality collaborative paper to domestic } \\
& =\frac{\text { High }- \text { quality collaborative papers with authors in different countries }}{\text { High - quality collaborative papers with domestic authors }}
\end{aligned}
$$

Capacity for protection of technological innovation was primarily measured by patent applications. Since patents integrate technical, economic, and legal information, these indicators can illustrate an organization's capability of technological innovation as well as their strength in technology transfer and protection of intellectual property. The indicators included the total number of patents, the total number of patent families, number of patents per family, percentage of valid patents (including active, pending, PCT designated stage) and global distribution. A patent family is a set of individual patents granted by various countries. Think of a patent family as all the equivalent patent applications corresponding to a single invention, covering different application documents in one or different geographical regions. The geographical regions in global distributions are counted by the intellectual property office of different regions because the patent is applied through the office. For instance, WIPO refers to the World Intellectual Property Organization, United States refers to United States Patent and Trademark Office, China refers to China National Intellectual Property Administration, Taiwan refers to Taiwan Intellectual Property Office, Hong Kong refers to Intellectual Property Department of the Government of the Hong Kong Special Administrative Region, EPO refers to European Patent Office, Netherlands refers to Netherlands Patent Office, etc.

\section{Results}

\subsection{Higher Scientific Output by Anhui and CAAS than other organizations}

Simple counting of published articles shows that Chinese organizations produced a greater number than those from Japan and India, as was also observed in the percentage of papers by core-authors. By contrast, CSIRI, Shizuoka, and NARO published more 
papers than other organizations from 2008 to 2011, which continually increased until 2014. However, tea research also significantly increased at Anhui and CAAS since 2011, while productivity by Tocklai increased more slowly (Fig. 1).

Table 1 shows the statistics for the 1551 total tea research papers published by the six selected organizations from Jan 2008 to Jul 2020. Anhui Agricultural University ranked first with 479 papers, 437 (91.23\%) of which were core author publications. The Chinese Academy of Agricultural Sciences, Tea Research Institute ranked second with 445 papers, including $388(87.19 \%)$ core author papers. The number three ranked organization, (CSIRI), the largest research and development organization in India which includes several tea research institutes, published a total of 220 papers, with core authorship in 189 (85.91\%). Among CSIRI institutes, the Institute of Himalayan Bioresource Technology (IHBT) published 100 papers, while the Central Food Technological Research Institute had 30 papers. Shizuoka ranked fourth with 157 papers, $128(81.53 \%)$ by core authors. A total of 154 papers, $102(66.23 \%)$ by core authors, were published by NARO, which contains three main tea research organizations. The NARO Institute of Vegetable \& Floriculture Science, restructured into the NARO Institute of Vegetable and Tea Science and NARO Institute of Floricultural Science in 2016, published 76 papers, while the NARO National Food Research Institute produced 47 papers, and the NARO Institute of Fruit Tree and Tea Science published 30 papers. Finally, 120 papers, $81(67.50 \%)$ by core authors, were published by Tocklai.

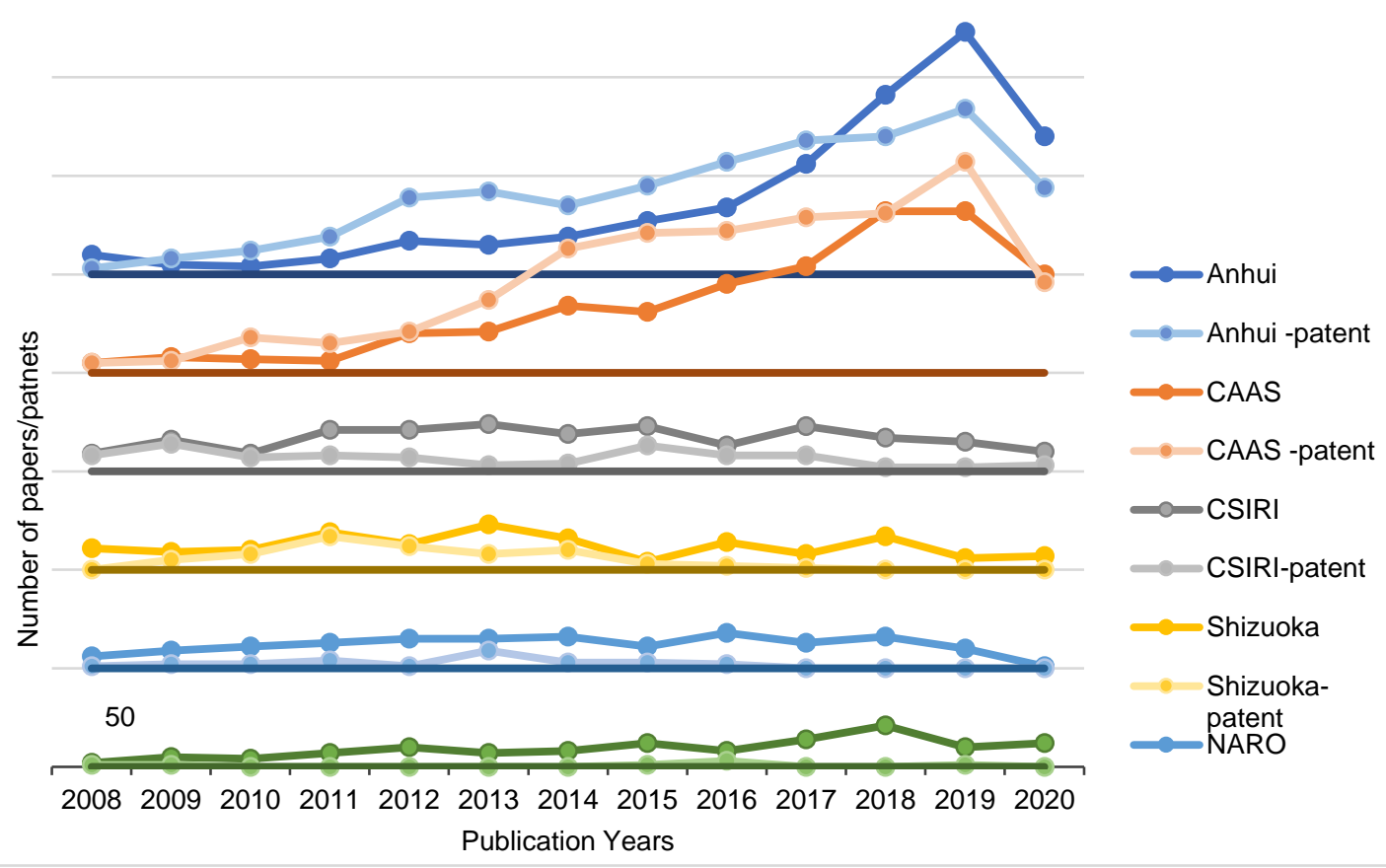

Figure 1. Number of Papers/Patents published/issued by the six organizations (Jan $2008 \sim$ Jul 2020)

Table 1. Bibliometric evaluation of paper indices for the six organizations (percentage)

\begin{tabular}{|c|c|c|c|c|c|c|c|}
\hline & Organizations & Anhui, China & CAAS, China & CSIRI, India & $\begin{array}{c}\text { Shizuoka, } \\
\text { Japan }\end{array}$ & $\begin{array}{l}\text { NARO, } \\
\text { Japan }\end{array}$ & $\begin{array}{c}\text { Tocklai, } \\
\text { India }\end{array}$ \\
\hline \multirow{2}{*}{$\begin{array}{c}\text { Scientific } \\
\text { output }\end{array}$} & Number of papers & 479 & 445 & 220 & 157 & 154 & 120 \\
\hline & Core author papers & $437(91.23 \%)$ & $388(87.19 \%)$ & $189(85.91 \%)$ & $128(81.53 \%)$ & $102(66.23 \%)$ & $81(67.5 \%)$ \\
\hline \multirow{3}{*}{$\begin{array}{l}\text { Academic } \\
\text { influence }\end{array}$} & $\begin{array}{c}\text { Percentage of non-self- } \\
\text { citations }\end{array}$ & $80.00 \%$ & $80.51 \%$ & $94.48 \%$ & $91.37 \%$ & $90.30 \%$ & $84.53 \%$ \\
\hline & $\begin{array}{c}\text { Average citations per } \\
\text { item }\end{array}$ & 14.27 & 14.57 & 17.88 & 17.41 & 10.71 & 9.64 \\
\hline & $\begin{array}{l}\text { Percentage of cited pa- } \\
\text { pers }\end{array}$ & $87.89 \%$ & $90.56 \%$ & $94.09 \%$ & $89.81 \%$ & $83.77 \%$ & $79.17 \%$ \\
\hline
\end{tabular}




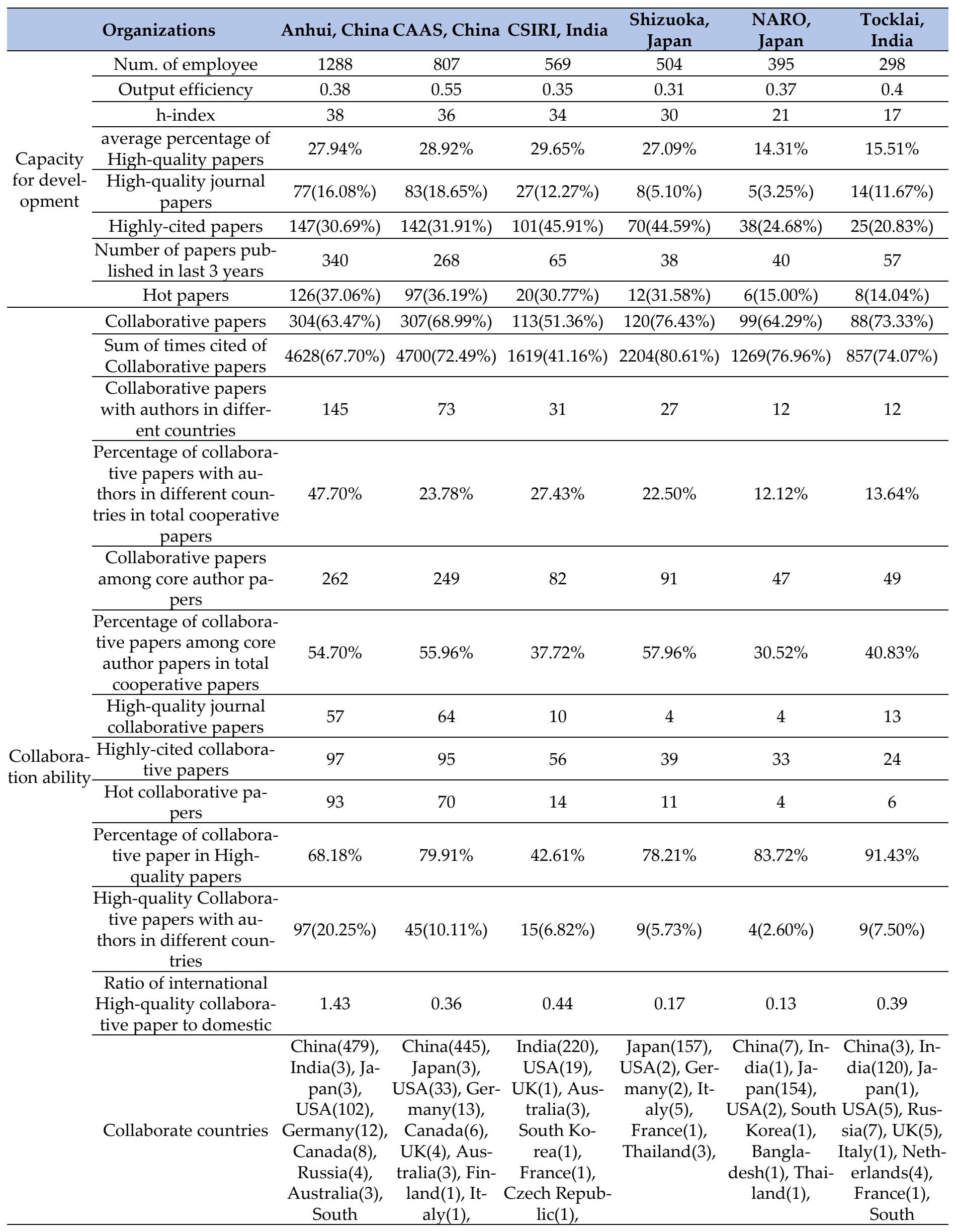




\begin{tabular}{|c|c|c|c|c|c|}
\hline Organizations & Anhui, China CAAS, China & CSIRI, India & $\begin{array}{c}\text { Shizuoka, } \\
\text { Japan }\end{array}$ & $\begin{array}{l}\text { NARO, } \\
\text { Japan }\end{array}$ & $\begin{array}{l}\text { Tocklai, } \\
\text { India }\end{array}$ \\
\hline & $\begin{array}{cc}\text { Korea(7), Fin- } & \text { Nether- } \\
\text { land(7), } & \text { lands(3), } \\
\text { France(1), } & \text { France(2), Sin- } \\
\text { Bangla- } & \text { gapore(5), } \\
\text { desh(4), Thai- } & \text { Denmark(4), } \\
\text { land(1), Bra- } & \text { New Zea- } \\
\text { zil(4), Czech land(2), South } & \text { land } \\
\text { Republic(2), Africa(1), Tur- } & \text { Arca- } \\
\text { New Zea- } & \text { key(1), } \\
\text { land(1), Bel- } & \\
\text { gium(2), Paki- } & \\
\text { stan(1), Swe- } & \\
\text { den(1), } & \end{array}$ & $\begin{array}{c}\text { Kenya(3), } \\
\text { Turkey(1), } \\
\text { Malaysia(1), } \\
\text { Nigeria(1), } \\
\text { Portugal(1), } \\
\text { Saudi Ara- } \\
\text { bia(1), }\end{array}$ & & $\begin{array}{c}\text { Chile(1), Sri } \\
\text { Lanka(1), }\end{array}$ & $\begin{array}{l}\text { Africa(2), Po- } \\
\text { land(1), }\end{array}$ \\
\hline
\end{tabular}

Scientific output can only show the organization's overall publication productivity in the field of tea research. In order to understand which research topics each organization specializes in and their competitiveness in this area at a given time, we carried out a detailed analysis of the distribution (proportions) of each institute's published research topics (Fig. 2). We found that most organizations produced papers across multiple, different research directions, in particular spanning tea and health (309 papers), tea plant genetics and breeding (297 papers), tea plant physiology and nutrition (260 papers), tea quality and risk assessment (237 papers), and flavor chemistry of tea (201 papers). Among these organizations, Anhui performed the most studies in tea plant genetics and breeding and flavor chemistry with $119(40.07 \%)$ and $80(39.8 \%)$ papers for each respective topic. The percentage here indicates the number of papers published one organization on a given topic relative to the total number of papers produced by all organizations for that topic. Thus, based on annual changes in research topic (Appendix A), Anhui has excelled considerably since 2016 in genetics and breeding as well as in flavor chemistry. In addition, Anhui also entered a rapid development stage in tea quality and risk assessment (79 papers) and in tea and health studies (80 papers) since 2014 (more than 5 articles published ever after).

Similarly, CAAS has four research directions for which they produced more than $40 \%$ of the published articles for those respective topics, including tea plant physiology and nutrition with $114(43.85 \%)$ papers, tea plant protection (84 papers, $43.30 \%)$, tea germplasm $(53,48.18 \%)$, and tea cultivation $(27,48.21 \%)$. Tea plant genetics and breeding $(103,34.68 \%)$ has also been an important research direction for the CAAS Tea Research Institute. While the number of papers published by CAAS in tea plant physiology and nutrition increased rapidly from 2012 to 2019, their productivity in tea plant genetics and breeding and tea plant protection steadily increased in the period from 2014 to 2019.

By contrast, CSIRI has published the largest proportion of studies on tea comprehensive processing, with 49 (30.43\%) total papers since 2013. The number two ranked research topic at CSIRI was tea plant genetics and breeding, having published 49 studies $(16.50 \%)$ from 2009 to 2014, while 48 papers (15.53\%) were published on tea and health by this organization since 2011.

Shizuoka performed the most research on Tea and Health $(107,34.63 \%)$ among the six organizations, comprising $68.16 \%$ of the tea research output by Shizuoka. Notably, 2013 was the most productive year for publication on tea and health at this organization, with 16 papers, although this output has declined slightly in recent years. The second most productive research focus at Shizuoka is tea flavor chemistry with 21 papers total, the highest productivity of which was between 2008 to 2010 .

NARO also had substantial productivity in tea and health $(56,19.12 \%)$, as well as in tea plant protection $(26,13.40 \%)$, flavor chemistry of tea $(24,11.94 \%)$, and tea plant physiology and nutrition $(25,9.62 \%)$. NARO has steadily developed their research program in 
tea and health since 2010, with an average of five papers per year, which accounts for $18.12 \%$ of the total papers in that research area. NARO also published the most papers in tea plant protection in 2016, with 6 papers.

Tea plant physiology and nutrition $(49,18.85 \%)$ and tea plant protection $(43,22.16 \%)$ were the two major research directions for Tocklai, which respectively accounted for $40.83 \%$ and $35.83 \%$ of their published studies, and $18.85 \%$ and $22.16 \%$ of the papers published in those research areas, respectively. Tocklai has steadily developed its research in these areas from 2008-2012, and the number of published articles rapidly increased since 2015. Tocklai also substantially contributed to research in tea quality and risk assessment $(21,8.86 \%)$, increasing in this area since 2011.

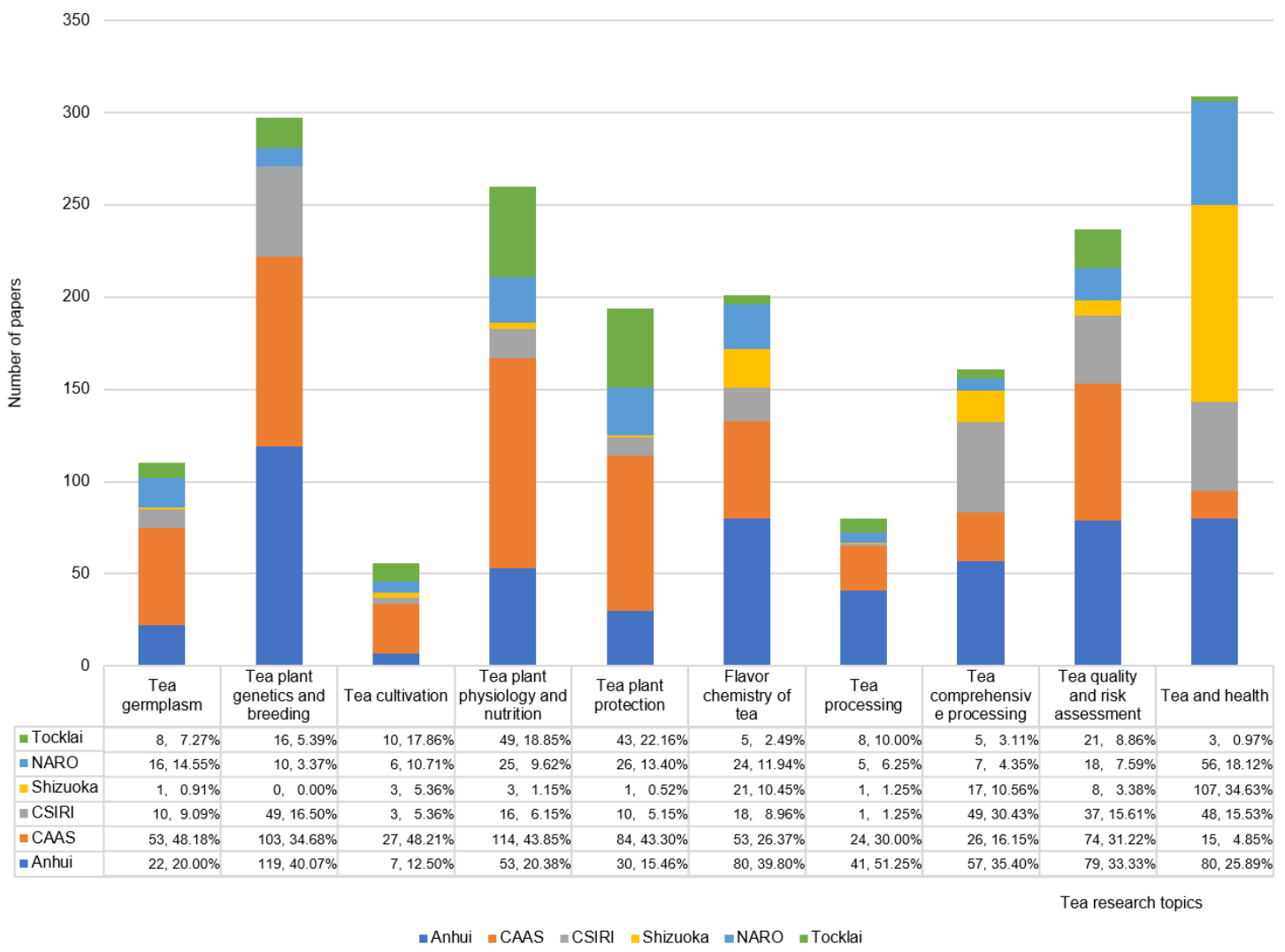

Figure 2. Proportions of tea research topics among papers produced by the six organizations.

\subsection{CSIRI and Shizuoka excelled in Academic influence}

Academic influence is another factor that can help demonstrate an organization's capacity for and competitiveness in research. We therefore investigated the strength of academic influence for each of the six organizations (Table 1 and Fig. 3a). The results showed that CSIRI ranked the highest in average citations per item (17.88) and in the percentage of non-self citations (94.48\%). By comparison, Shizuoka also had a high average citations per item (17.41) and percentage of non-self citations (91.37\%). NARO ranked third for percentage of non-self-citations $(90.30 \%)$.

Despite high publication numbers, Anhui and CAAS were not highly ranked based on their citation numbers. CAAS ranked third in average citations per item (14.57), while Anhui and CAAS ranked first and second, respectively, for the sum of times cited, which is at least partially attributable to their high total number of published papers.

To investigate how total citations reflected research growth, we analyzed the sum of times cited per year for each of the six tea research organizations, as shown in Fig.3b. Again, Anhui and CAAS showed the fastest growth in number of times cited. Prior to 2018, the number of the sum of times cited per year by CAAS was higher than that of Anhui, whereas after 2018, Anhui surpassed CAAS in the growth of number of times 
cited. Shizuoka has higher number of the sum of times cited in 2008 and 2011, after 2011 the number was reduced until 2015, and since then there has been a slight increase. The sum of times cited per year for CSIRI and Tocklai has declined annually since 2015, and NARO since 2016.

3.3 High-quality papers, output efficiency, and h-index contribute to capacity for development and overall academic competitiveness.

While influence can be a strong indicator of past reputation, metrics for research development can potentially show the strength of both past and future research influence. We therefore introduced the capacity for development to reflect each organization's ability to produce more high quality papers and maintain a leading position as research fields develop.

We compared the strength of potential development among all six organizations (Fig. $3 \mathrm{c}$ and Fig. 3d). The specific values for each of the following parameters are shown in Table 1. Comparison of output efficiency (Fig. 3c) showed that CAAS (0.55) ranked higher than Anhui (0.38), while Tocklai ranked second (0.40). The h-index of Anhui (38) was higher than that of CAAS (36). The average percentage of High-quality papers of CSIRI ranked first $(29.65 \%)$, followed by CAAS (28.92\%), Anhui (27.94\%), and Shizuoka $(27.09 \%)$.

To investigate which High-quality papers contributed most to the capacity for development of the six tea research organizations, we analyzed the percentage of High-quality journal papers, Highly-cited papers, and Hot papers (Fig. 3d). CAAS ranked first in the number and percentage of High-quality journal papers (83, 18.65\%), followed by Anhui $(77,16.08 \%)$, while Anhui ranked first in the number and percentage of Hot papers (340, $37.06 \%)$, with CAAS ranking second $(268,36.19 \%)$. CSIRI ranked first in the percentage of Highly-cited papers (45.91\%) and Shizuoka ranked second (44.59\%), while Anhui ranked first in the number of Highly-cited papers (147) (Fig. 3d, Table 1).

\subsection{Ability to collaborate contributes to higher citations and more High-quality papers}

Ability to collaborate also represents an important factor in an organization's capacity for development. Investigation of metrics related to collaboration revealed that Shizuoka performed the highest in collaborative outputs, followed by Tocklai. In particular, Shizuoka had the highest percentage of citations for papers with collaborating authors $(80.61 \%)$ and higher percentage of papers with collaborating authors $(76.43 \%)$, as well as a higher percentage of collaborative papers among core author papers $(57.96 \%)$ (Table 1 and Fig. 3e). 


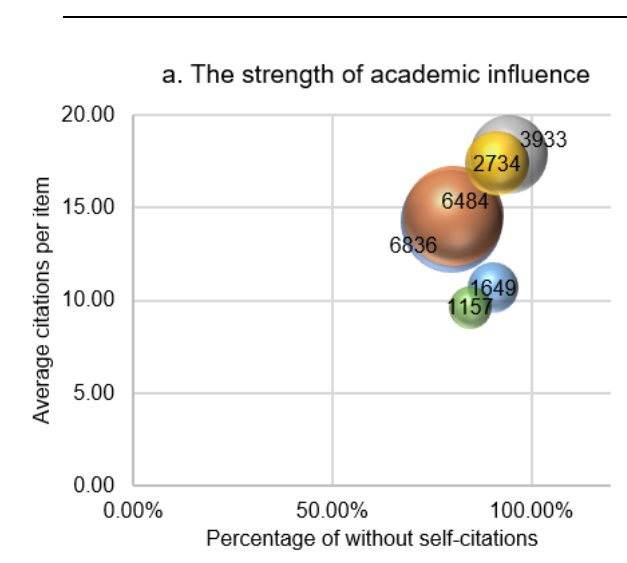

The size of the bubbles=Sum of times cited.

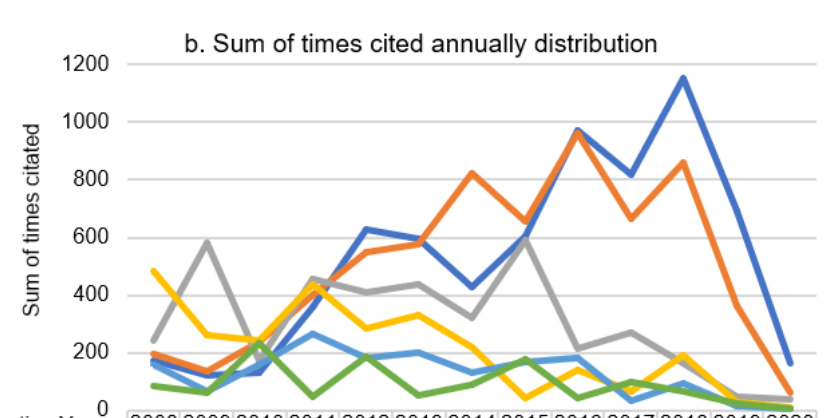

Publication Year 2008200920102011201220132014201520162017201820192020 $\begin{array}{lllllllllllllll}\text { - Anhui } & 173 & 119 & 130 & 360 & 626 & 594 & 428 & 603 & 972 & 820 & 1155 & 694 & 162\end{array}$ $\begin{array}{lllllllllllllllll}\text { CCAAS } & 194 & 136 & 238 & 402 & 547 & 577 & 825 & 656 & 964 & 665 & 860 & 361 & 59\end{array}$ $\begin{array}{lllllllllllllllll}- \text { CSIRI } & 242 & 580 & 172 & 457 & 410 & 437 & 319 & 589 & 213 & 269 & 162 & 46 & 37\end{array}$ \begin{tabular}{l|l|l|l|l|l|l|l|l|l|l|l|l|l|}
\hline -Shizuoka & 483 & 261 & 244 & 437 & 284 & 331 & 218 & 43 & 139 & 65 & 189 & 29 & 11 \\
\hline
\end{tabular}

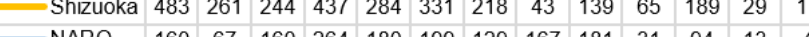
\begin{tabular}{ll|lllllllllllllll} 
—NARO & 160 & 67 & 160 & 264 & 180 & 199 & 129 & 167 & 181 & 31 & 94 & 13 & 4 \\
\hline
\end{tabular}

d. Percentage of high-quality papers

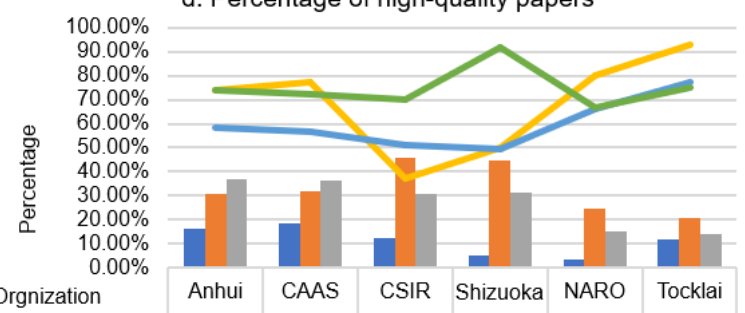

Orgnization

Anhui CAAS CSIR Shizuoka NARO Tocklai

Percentage of high-

quality journal papers

\begin{tabular}{|l|l|l|l|l|l|l}
\hline $12.27 \%$ & $18.65 \%$ & $12.27 \%$ & $3.25 \%$ & $11.67 \%$ & \\
\hline
\end{tabular}

\begin{tabular}{|l|l|l|l|l|l|}
\hline $30.69 \%$ & $31.91 \%$ & $45.91 \%$ & $44.59 \%$ & $24.68 \%$ & $20.83 \%$ \\
\hline
\end{tabular}

\begin{tabular}{|l|l|l|l|l|l|}
$37.06 \%$ & $36.19 \%$ & $30.77 \%$ & $31.58 \%$ & $15.00 \%$ & $14.04 \%$ \\
\hline
\end{tabular}

\begin{tabular}{|l|l|l|l|l|l|}
\hline $74.03 \%$ & $77.11 \%$ & $37.04 \%$ & $50.00 \%$ & $80.00 \%$ & $92.86 \%$ \\
\hline
\end{tabular}

Collaborative high-

quality journal papers

\begin{tabular}{l|l|l|l|l|l|l|}
\hline $\begin{array}{c}\text { Percentage of } \\
\text { Collaborative highly cited }\end{array}$ & $58.43 \%$ & $56.55 \%$ & $50.91 \%$ & $49.37 \%$ & $66.00 \%$ & $77.42 \%$ \\
\hline
\end{tabular} \begin{tabular}{c|c|c|c|c|c|c|} 
Papers & & & & & \\
\hline
\end{tabular} e. The strength of collaboration

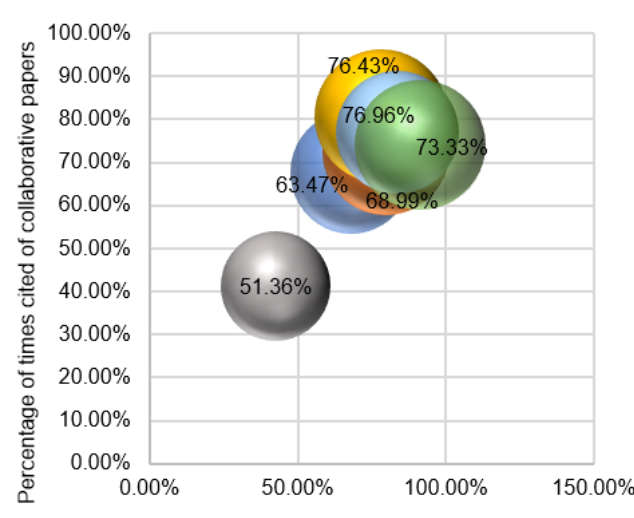

Percentage of collaborative paper in High-qulity papers The size of the bubbles= Percentage of Collaborative papers.

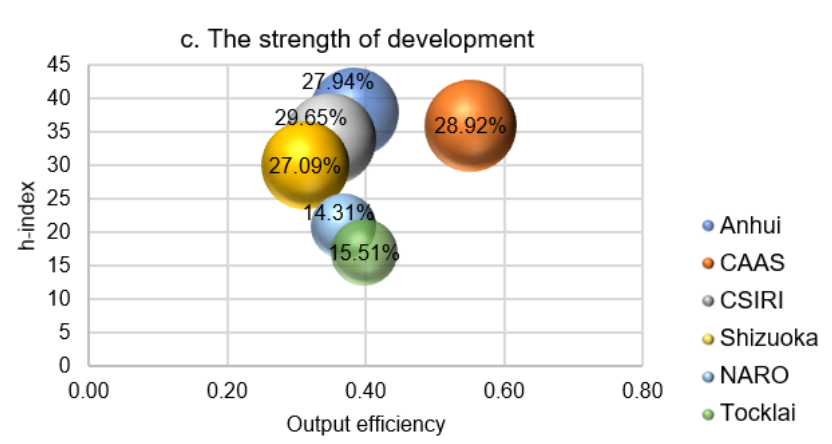

The size of the bubbles=Average percentage of high quality papers.

The Ratio of international High-quality collaborative paper to domestic

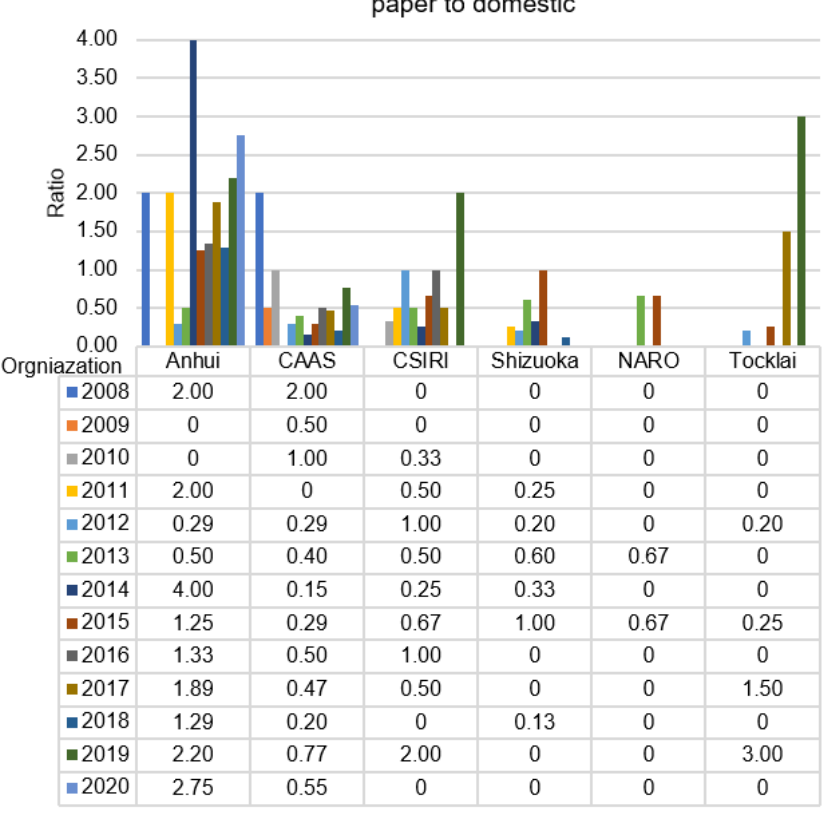

Figure 3. Comparison of the strength of the research output among the six major tea research organizations. 
Tocklai had the highest percentage of collaborative paper in High-quality papers $(91.43 \%)$, and a high percentage of papers with collaborating authors $(73.33 \%)$ and a high percentage of citations for papers with collaborating authors (74.07\%), but a lower percentage of core author collaborative papers (40.83\%). NARO ranked first in percentage of citations for papers with collaborating authors (76.96\%), and had a higher percentage of collaborative paper in High-quality papers (83.72\%). Interestingly, Anhui showed the highest number of collaborative papers among core author publications (262), while CAAS had the greatest sum of total citations for papers with collaborating authors (4700) in addition to the highest percentage of core author collaborative papers $(55.96 \%)$.

Further details about the contribution of collaborative papers to the academic competitiveness of the six research organizations are shown in Table 1, Fig. $3 \mathrm{~d}$ and Fig. $3 \mathrm{f}$. Surprisingly, we found that collaborative papers comprised more than $50 \%$ of total papers for each organization, with the exception of CSIRI. Among them, Tocklai had the highest proportion of collaborative papers, and the percentage of collaborative High-quality journal papers, Highly-cited papers, and Hot papers were $92.86 \%, 77.42 \%$, and $75.00 \%$, respectively (Fig. 3d). Cooperative papers also provided a strong contribution to academic competitiveness for Shizuoka through Hot papers (91.67\%) and Highly-cited papers (50.00\%).

The numbers and percentage of collaborative papers with the collaborating authors located in different countries are shown in Table 1. In these instances, Anhui had the highest numbers and percentage of studies with collaborating authors in different countries (145 articles, $47.70 \%$ of the total collaborative papers (304)), and the highest ratio of international High-quality collaborative paper to domestic (1.43). Further data mining showed that the majority of collaborating authors with Anhui were from the United States (102 papers) followed by Germany (12), Canada (8), Finland (7), and South Korea (7). CAAS (33) and CSIRI (19) also published the most papers in cooperation with the United States, and Shizuoka with Italy (5), NARO with China (7), and Tocklai with Russia (7). Thus, among the six tea research organizations, Anhui showed the most substantial increase in the ratio of international High-quality collaborative papers to domestic beginning in 2011, while CAAS (the ratio is 0.36) showed a similar, but weaker influence in international collaborations compared with domestic cooperation. CSIRI ranked second in the ratio (0.44). International collaborations had played an effective role in academic competitiveness of Tocklai (the ratio is 0.39 ) in recent years (Fig. 3f).

\subsection{Anhui, CAAS, and Tocklai show lower capacity for protection of intellectual property and technological innovations}

From Jan 2008 to Jul 2020, a total of 1016 patents, including 708 DWPI patent families, were cumulatively issued to the six major tea research organizations. Among them, as shown in Fig. 4 and Table 2, CAAS ranked first with 621 patents (446 families), while Anhui ranked second with 526 patents (403 families), followed by CSIRI with 87 patents (40 families), Shizuoka with 66 patents (12 families), NARO with 27 patents (9 families), and finally Tocklai with 7 patents (7 families). We found that although CAAS and Anhui were each issued a large number of patents, their average number of patents per family was only 1.3 and 1.4, respectively, while Shizuoka held the most patents per family at 5.5, indicating greater international legal protection for their technological innovations. 


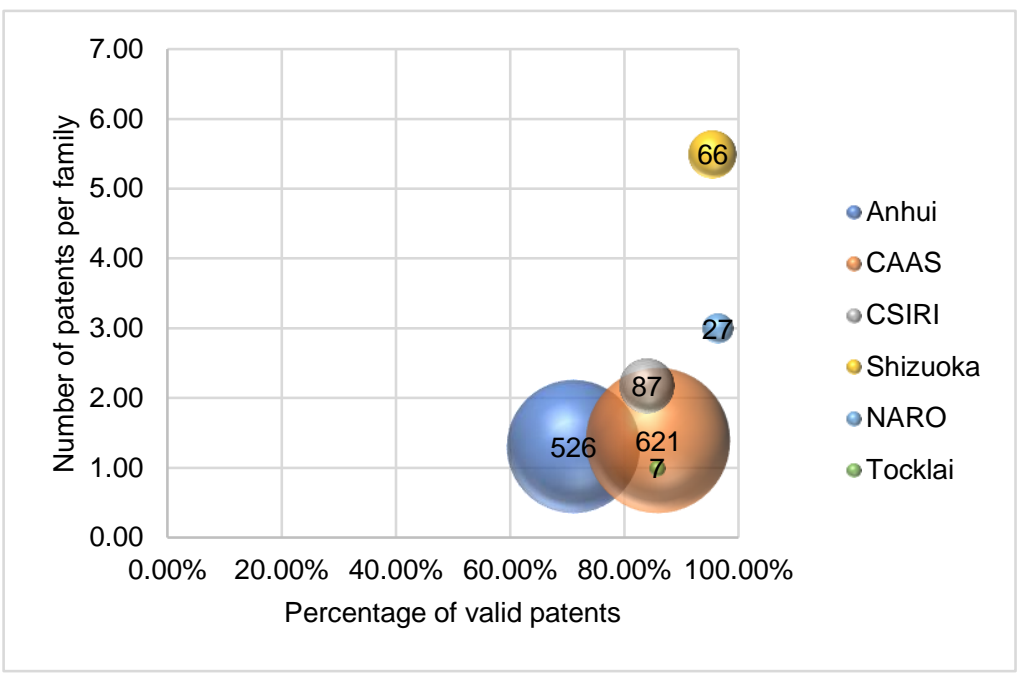

Figure 4. The strength of protection for technological innovations among the six major tea research organizations.

Note: The size of the bubbles=Num. of patents.

Table 2. Bibliometric evaluation of patent indices for the six organizations (percentage)

\begin{tabular}{|c|c|c|c|c|c|c|c|}
\hline \multicolumn{2}{|c|}{ Organizations } & $\begin{array}{l}\text { Anhui, } \\
\text { China }\end{array}$ & $\begin{array}{l}\text { CAAS, } \\
\text { China }\end{array}$ & CSIRI, India & $\begin{array}{c}\text { Shizuoka, } \\
\text { Japan }\end{array}$ & $\begin{array}{l}\text { NARO, } \\
\text { Japan }\end{array}$ & $\begin{array}{l}\text { Tocklai, } \\
\text { India }\end{array}$ \\
\hline \multirow[b]{5}{*}{$\begin{array}{l}\text { Capacity } \\
\text { for pro- } \\
\text { tection of } \\
\text { techno- } \\
\text { logical in- } \\
\text { novation }\end{array}$} & $\begin{array}{l}\text { Patent appli- } \\
\text { cation (patent } \\
\text { family) }\end{array}$ & $526(403)$ & $621(446)$ & $87(40)$ & $66(12)$ & $27(9)$ & $7(7)$ \\
\hline & $\begin{array}{c}\text { Number of } \\
\text { patents per } \\
\text { family }\end{array}$ & 1.3 & 1.4 & 2.2 & 5.5 & 3.0 & 1.0 \\
\hline & Valid Patent & $374(71.10 \%)$ & $534(85.99 \%)$ & $73(83.91 \%)$ & $63(95.45 \%)$ & $26(96.30 \%)$ & $6(85.71 \%)$ \\
\hline & $\begin{array}{c}\text { Foreign dis- } \\
\text { tribution }\end{array}$ & $0(0.00 \%)$ & $5(0.81 \%)$ & $81(93.10 \%)$ & $45(68.18 \%)$ & $27(100.00 \%)$ & $0(0.00 \%)$ \\
\hline & $\begin{array}{l}\text { Global distri- } \\
\text { bution (Rec- } \\
\text { ords) }\end{array}$ & China(526) & $\begin{array}{l}\text { China(616);W } \\
\text { IPO(2);Ja- } \\
\text { pan(1);Neth- } \\
\text { erlands(2) }\end{array}$ & $\begin{array}{l}\text { WIPO(19);Ch } \\
\text { ina(10);Ja- } \\
\text { pan(3);In- } \\
\text { dia(6);United } \\
\text { States(26); } \\
\text { EPO(8);South } \\
\text { Ko- } \\
\text { rea(3);Aus- } \\
\text { tralia(3);Ger- } \\
\text { many(3);Can- } \\
\text { ada(2);Spain( } \\
\text { 1);Malay- } \\
\text { sia(1);Spain(1 } \\
\text { );Mex- } \\
\text { ico(1);South } \\
\text { Af- } \\
\text { rica(1);Mex- } \\
\text { ico(1);Rus- } \\
\text { sia(1);Vi- } \\
\text { etnam(1) }\end{array}$ & 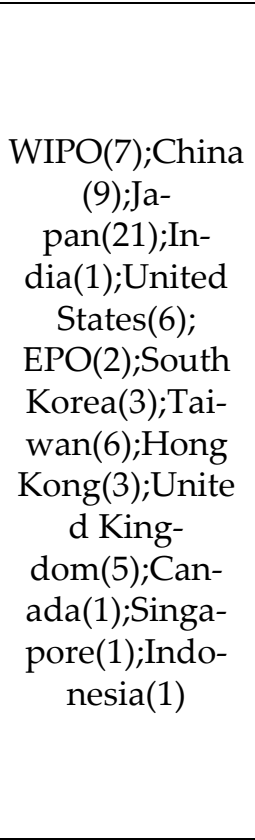 & $\begin{array}{l}\text { WIPO(5);Chi } \\
\text { na(6);United } \\
\text { States(4);EPO } \\
\text { (7);South Ko- } \\
\text { rea(1);Hong } \\
\text { Kong, } \\
\text { China(3);Aus } \\
\text { tralia(1) }\end{array}$ & India(7) \\
\hline
\end{tabular}

Fig. 1 shows the distribution of patents per year for all six organizations. Due to the delay in time between patent application and publication (up to 30 months, including a 12-month priority period and an 18-month publication period), so the annual number of issued patents between Jan 2008 to Jul 2020 may actually represent the fruition of much earlier applications and research, and also does not show how many patents are awaiting 
approval. We found that CSIRI applied for more patents than other organizations before 2010. However, while the number of patent applications from other organizations have declined in recent years, patent applications from CAAS and Anhui have rapidly increased, potentially due to incentivization by the Chinese government through the National Medium and Long-term Science and Technology Development Plan (2006-2020) ${ }^{\text {[26] }}$.

Details on the legal status and Intellectual Property Administration of states in which patent applications were submitted by the six organizations are listed in Table 2. NARO ranked first both in percentage of valid patents $(96.30 \%)$ and percentage of patents that are also held in nations apart from that of the organization (i.e., their foreign distribution) $(100 \%)$, while Shizuoka ranked second in valid patents $(95.45 \%)$ and CSIRI ranked second in percentage of foreign distribution (93.10\%). Interestingly, we found that NARO obtained the greatest number of foreign patents to the EPO (7), followed by China (6), and the United States (4). By contrast, outside of Japan, Shizuoka was found to hold the most foreign patents in China (9), followed by the United States (6), and Taiwan (6). Among all six organizations, CSIRI had the largest number of international patents (81 in countries outside of India) and held patents across the largest number of foreign countries. CSIRI applied for the most patents in the United States (26), but held only 9 in China and 8 in EPO. Although CAAS and Anhui applied for several times as many patents as other organizations, very few patents were submitted to countries outside of China and also had a low proportion of valid patents. In particular, CAAS was found to have only two patents in the Netherlands and one in Japan, while Anhui holds no patents outside of China.

\section{Discussion}

This comparative analysis of publications and patents by the six major tea research organizations shows that the largest Chinese organizations conducting tea-related research have recently undergone rapid growth in their scientific and technological output. In particular, the growth and capacity for further output by CAAS and Anhui are reflected by the relatively high quantity of papers and patents, the broad range of research topics (spanning 10 tea-related sub-disciplines), and the high number and percentage of Highquality papers.

Two main factors appear to drive this development. First, in 2012, China embarked on a strategy of increased financial investment in agricultural science and technology to modernize agriculture, especially supporting technology transfer and extension ${ }^{[27]}$. Second, the tea industry in particular has developed rapidly as the recipient of local, provincial, and national governmental funds through implementation of nationwide plans to alleviate poverty in $2015^{[28]}$ and rural revitalization in 2018 ${ }^{[29]}$.

However, despite the recent growth in research output, the academic influence of papers published by Chinese organizations is relatively low compared with other organizations, reflected by metrics for average citations, percentage of non-self-citation, and percentage of Highly-cited papers, etc. These findings combined with metrics showing lower collaboration and international collaboration show that competitiveness and academic influence are tied to international collaboration. For example, Shizuoka and CSIRI published a greater number of international collaboration studies during the early years covered by our survey. By contrast, Anhui shifted greater focus to international cooperation within the past five years, significantly increasing the number of papers with foreign collaborating authors and subsequently increasing the relative academic influence of its publications.

This study also showed that the number of patent applications submitted by Chinese tea research organizations is relatively high compared with the major Japanese and Indian tea research organizations. However, the intellectual property rights for inventions by Anhui and CAAS are not protected by patents internationally, as indicated by the comparatively low percentage of valid patents, number of patents per family, and percentage of patents held in other countries. 
The number of papers and patents published annually by Shizuoka and NARO in tea research has not increased significantly in recent years, although Japan has a richer variety of tea-related products. This may be attributable, at least in part, to their relatively high productivity in applied technology research (e.g., tea and health, flavor chemistry of tea) compared with the main research topics of Anhui and CAAS, which focus on basic research (e.g., tea germplasm, tea plant physiology, and nutrition).

Comparison of High-quality papers shows that Shizuoka and NARO published fewer High-quality papers, but their papers garnered more citations. This finding shows that number of High-quality journals papers and number of Highly-cited papers are not necessarily strongly correlated in tea research. Furthermore, Shizuoka and NARO applied for more international patents and formed more patent families than other organizations, which is also a manifestation of their better developed tea-related technology.

CSIRI produced more studies about tea comprehensive processing, tea and health, and tea genetics and breeding, covering both basic and applied technology tea research areas. It had high academic influence and applied for many international patents. The articles from Tocklai mainly focused on basic research, such as tea tree physiology and nutrition and pest management. In addition, cooperation with other institutions increased Tocklai's academic influence, evident in the highest proportion of collaborative paper in High-quality papers and the relatively high proportion of citations for collaborative papers relative to total citations.

It also warrants mention that, cumulatively, the largest proportion of international collaborative papers for all six tea research organizations were produced with authors from the United States. In addition, CSIRI, Shizuoka, and NARO all hold patents for tearelated innovations in the United States, indicating that this market is also a major source of tea product revenue.

Author Contributions: Conceptualization, methodology, H.Z. and X.Y; software, formal analysis, investigation, visualization, writing-original draft preparation, H.Z. and J.W.; resources, validation, X.X.; data curation, H.Z. and X.X.; writing - review and editing, X.Y. and X.X. project administration, funding acquisition, X.X. and J.W.; All authors have read and agreed to the published version of the manuscript.

Funding: This work was supported by the Central Public-Interest Scientific Institution Basal Research Fund (NO.1610212017018), nine Innovative Research Teams including Tea Germplasm Innovative Research Team in Tea Research Institute, Chinese Academy of Agricultural Sciences.

Acknowledgments: The authors would like to thank Kong Lingbo, Lin Qiao and He Wei from the Agricultural Information Institute of CAAS for their help and support.

Conflicts of Interest: The authors declare no conflict of interest.

\section{Appendix A}

Table A1. Number of publications in ten tea research topics between January 2008 and July 2020

\begin{tabular}{|c|c|c|c|c|c|c|c|c|c|c|c|}
\hline $\begin{array}{l}\text { Organiza- } \\
\text { tions }\end{array}$ & $\begin{array}{l}\text { Publica- } \\
\text { tion Years }\end{array}$ & $\begin{array}{c}\text { Tea } \\
\text { Germplasm }\end{array}$ & $\begin{array}{l}\text { Tea plant } \\
\text { genetics } \\
\text { and } \\
\text { breeding }\end{array}$ & $\begin{array}{c}\text { Tea } \\
\text { culti- } \\
\text { vation }\end{array}$ & $\begin{array}{l}\text { Tea plant } \\
\text { physiol- } \\
\text { ogy and } \\
\text { nutrition }\end{array}$ & $\begin{array}{c}\text { Tea } \\
\text { plant } \\
\text { protec- } \\
\text { tion }\end{array}$ & $\begin{array}{c}\text { Flavor } \\
\text { chem- } \\
\text { istry } \\
\text { of tea }\end{array}$ & $\begin{array}{c}\text { Tea } \\
\text { pro- } \\
\text { cessing }\end{array}$ & $\begin{array}{l}\text { Tea Com- } \\
\text { prehen- } \\
\text { sive Pro- } \\
\text { cessing }\end{array}$ & $\begin{array}{l}\text { Tea qual- } \\
\text { ity and } \\
\text { Risk as- } \\
\text { sessment }\end{array}$ & $\begin{array}{c}\text { Tea } \\
\text { and } \\
\text { Health }\end{array}$ \\
\hline \multirow{8}{*}{ Anhui } & 2008 & 0 & 4 & 0 & 1 & 0 & 0 & 1 & 2 & 1 & 1 \\
\hline & 2009 & 0 & 2 & 0 & 0 & 0 & 1 & 0 & 1 & 1 & 0 \\
\hline & 2010 & 0 & 0 & 0 & 0 & 0 & 3 & 0 & 0 & 1 & 0 \\
\hline & 2011 & 0 & 1 & 0 & 2 & 1 & 2 & 0 & 0 & 2 & 1 \\
\hline & 2012 & 1 & 5 & 2 & 2 & 1 & 4 & 0 & 2 & 1 & 2 \\
\hline & 2013 & 0 & 3 & 0 & 2 & 0 & 3 & 0 & 0 & 4 & 4 \\
\hline & 2014 & 2 & 3 & 0 & 4 & 1 & 4 & 1 & 2 & 1 & 7 \\
\hline & 2015 & 1 & 2 & 0 & 1 & 0 & 7 & 5 & 4 & 4 & 9 \\
\hline
\end{tabular}




\begin{tabular}{|c|c|c|c|c|c|c|c|c|c|c|c|}
\hline $\begin{array}{c}\text { Organiza- } \\
\text { tions }\end{array}$ & $\begin{array}{l}\text { Publica- } \\
\text { tion Years }\end{array}$ & $\begin{array}{c}\text { Tea } \\
\text { Germplasm }\end{array}$ & $\begin{array}{l}\text { Tea plant } \\
\text { genetics } \\
\text { and } \\
\text { breeding }\end{array}$ & $\begin{array}{c}\text { Tea } \\
\text { culti- } \\
\text { vation }\end{array}$ & $\begin{array}{l}\text { Tea plant } \\
\text { physiol- } \\
\text { ogy and } \\
\text { nutrition }\end{array}$ & $\begin{array}{c}\text { Tea } \\
\text { plant } \\
\text { protec- } \\
\text { tion } \\
\end{array}$ & $\begin{array}{c}\text { Flavor } \\
\text { chem- } \\
\text { istry } \\
\text { of tea }\end{array}$ & $\begin{array}{c}\text { Tea } \\
\text { pro- } \\
\text { cessing }\end{array}$ & $\begin{array}{l}\text { Tea Com- } \\
\text { prehen- } \\
\text { sive Pro- } \\
\text { cessing }\end{array}$ & $\begin{array}{c}\text { Tea qual- } \\
\text { ity and } \\
\text { Risk as- } \\
\text { sessment }\end{array}$ & $\begin{array}{c}\text { Tea } \\
\text { and } \\
\text { Health }\end{array}$ \\
\hline & 2016 & 2 & 5 & 0 & 6 & 4 & 5 & 1 & 4 & 8 & 8 \\
\hline & 2017 & 4 & 20 & 1 & 5 & 3 & 6 & 2 & 7 & 11 & 9 \\
\hline & 2018 & 1 & 35 & 2 & 12 & 4 & 18 & 7 & 4 & 10 & 18 \\
\hline & 2019 & 6 & 25 & 2 & 8 & 13 & 13 & 13 & 23 & 23 & 15 \\
\hline & 2020 & 5 & 14 & 0 & 10 & 3 & 14 & 9 & 7 & 11 & 6 \\
\hline \multirow{13}{*}{ CAAS } & 2008 & 2 & 1 & 0 & 1 & 0 & 0 & 0 & 1 & 1 & 0 \\
\hline & 2009 & 2 & 1 & 0 & 1 & 1 & 1 & 0 & 1 & 3 & 0 \\
\hline & 2010 & 2 & 2 & 0 & 2 & 1 & 0 & 0 & 0 & 1 & 1 \\
\hline & 2011 & 0 & 0 & 1 & 2 & & 1 & 0 & 1 & 1 & 0 \\
\hline & 2012 & 6 & 4 & 1 & 6 & 4 & 2 & 0 & 2 & 4 & 0 \\
\hline & 2013 & 1 & 4 & 2 & 7 & 2 & 1 & 1 & 3 & 4 & 0 \\
\hline & 2014 & 5 & 10 & 0 & 12 & 11 & 3 & 0 & 2 & 6 & 2 \\
\hline & 2015 & 6 & 9 & 1 & 8 & 7 & 4 & 0 & 1 & 6 & 2 \\
\hline & 2016 & 6 & 16 & 3 & 10 & 9 & 6 & 0 & 1 & 8 & 1 \\
\hline & 2017 & 6 & 10 & 4 & 16 & 9 & 4 & 5 & 4 & 11 & 4 \\
\hline & 2018 & 6 & 20 & 7 & 25 & 15 & 13 & 7 & 3 & 8 & 2 \\
\hline & 2019 & 8 & 15 & 5 & 13 & 17 & 12 & 5 & 4 & 15 & 2 \\
\hline & 2020 & 3 & 11 & 3 & 11 & 8 & 6 & 6 & 2 & 6 & 1 \\
\hline \multirow{13}{*}{ CSIRI } & 2008 & 1 & 4 & 0 & 0 & 0 & 1 & 0 & 0 & 3 & \\
\hline & 2009 & 2 & 7 & 0 & 3 & 1 & 2 & 0 & 1 & 1 & 1 \\
\hline & 2010 & 1 & 3 & 0 & 0 & 0 & 1 & 0 & 2 & 1 & 2 \\
\hline & 2011 & 1 & 4 & 0 & 4 & 0 & 3 & 0 & 1 & 4 & 5 \\
\hline & 2012 & 1 & 9 & 0 & 1 & 0 & 1 & 0 & 3 & 6 & 1 \\
\hline & 2013 & 3 & 7 & 1 & 1 & 1 & 2 & 0 & 4 & 5 & 4 \\
\hline & 2014 & 0 & 5 & 0 & 1 & 2 & 0 & 0 & 5 & 3 & 4 \\
\hline & 2015 & 1 & 2 & 0 & 1 & 1 & 5 & 0 & 7 & 3 & 7 \\
\hline & 2016 & 0 & 2 & 0 & 1 & 2 & 2 & 0 & 4 & 2 & 3 \\
\hline & 2017 & 0 & 3 & 0 & 2 & 0 & 0 & 0 & 6 & 5 & 8 \\
\hline & 2018 & 0 & 0 & 1 & 1 & 2 & 1 & 1 & 8 & 3 & 3 \\
\hline & 2019 & 0 & 2 & 0 & 1 & 1 & 0 & 0 & 4 & 0 & 7 \\
\hline & 2020 & 0 & 1 & 1 & 0 & 0 & 0 & 0 & 3 & 1 & 3 \\
\hline \multirow{13}{*}{ Shizuoka } & 2008 & 0 & 0 & 1 & 0 & 5 & 0 & 0 & 0 & 0 & 5 \\
\hline & 2009 & 0 & 0 & 0 & 0 & 1 & 0 & 1 & 0 & 0 & 7 \\
\hline & 2010 & 0 & 0 & 0 & 0 & 4 & 0 & 0 & 0 & 0 & 6 \\
\hline & 2011 & 0 & 0 & 1 & 1 & 2 & 1 & 4 & 0 & 0 & 11 \\
\hline & 2012 & 0 & 0 & 0 & 0 & 2 & 0 & 1 & 0 & 0 & 10 \\
\hline & 2013 & 0 & 0 & 0 & 0 & 2 & 0 & 2 & 4 & 0 & 16 \\
\hline & 2014 & 0 & 0 & 0 & 0 & 2 & 0 & 3 & 1 & 0 & 11 \\
\hline & 2015 & 0 & 0 & 0 & 0 & 0 & 0 & 0 & 0 & 0 & 4 \\
\hline & 2016 & 0 & 1 & 0 & 0 & 2 & 0 & 3 & 0 & 0 & 8 \\
\hline & 2017 & 0 & 0 & 0 & 0 & 0 & 0 & 1 & 0 & 0 & 7 \\
\hline & 2018 & 0 & 2 & 1 & 0 & 1 & 0 & 1 & 2 & 0 & 12 \\
\hline & 2019 & 1 & 0 & 0 & 0 & 0 & 0 & 0 & 0 & 0 & 5 \\
\hline & 2020 & 0 & 0 & 0 & 0 & 0 & 0 & 1 & 1 & 0 & 5 \\
\hline \multirow{2}{*}{ NARO } & 2008 & 1 & 1 & 0 & 1 & 1 & 2 & 1 & 0 & 1 & 1 \\
\hline & 2009 & 2 & 1 & 0 & 1 & 1 & 2 & 0 & 0 & 1 & 3 \\
\hline
\end{tabular}




\begin{tabular}{|c|c|c|c|c|c|c|c|c|c|c|c|}
\hline $\begin{array}{l}\text { Organiza- } \\
\text { tions }\end{array}$ & $\begin{array}{l}\text { Publica- } \\
\text { tion Years }\end{array}$ & $\begin{array}{c}\text { Tea } \\
\text { Germplasm }\end{array}$ & $\begin{array}{l}\text { Tea plant } \\
\text { genetics } \\
\text { and } \\
\text { breeding }\end{array}$ & $\begin{array}{c}\text { Tea } \\
\text { culti- } \\
\text { vation }\end{array}$ & $\begin{array}{l}\text { Tea plant } \\
\text { physiol- } \\
\text { ogy and } \\
\text { nutrition }\end{array}$ & $\begin{array}{c}\text { Tea } \\
\text { plant } \\
\text { protec- } \\
\text { tion }\end{array}$ & $\begin{array}{c}\text { Flavor } \\
\text { chem- } \\
\text { istry } \\
\text { of tea }\end{array}$ & $\begin{array}{c}\text { Tea } \\
\text { pro- } \\
\text { cessing }\end{array}$ & $\begin{array}{l}\text { Tea Com- } \\
\text { prehen- } \\
\text { sive Pro- } \\
\text { cessing }\end{array}$ & $\begin{array}{l}\text { Tea qual- } \\
\text { ity and } \\
\text { Risk as- } \\
\text { sessment }\end{array}$ & $\begin{array}{c}\text { Tea } \\
\text { and } \\
\text { Health }\end{array}$ \\
\hline & 2010 & 2 & 1 & 0 & 1 & 1 & 1 & 0 & 1 & 1 & 6 \\
\hline & 2011 & 3 & 2 & 1 & 3 & 3 & 2 & 0 & 1 & 0 & 4 \\
\hline & 2012 & 3 & 3 & 0 & 2 & 1 & 3 & 0 & 1 & 2 & 4 \\
\hline & 2013 & 1 & 0 & 0 & 2 & 2 & 4 & 0 & 0 & 2 & 8 \\
\hline & 2014 & 1 & 0 & 0 & 4 & 3 & 2 & 1 & 3 & 1 & 4 \\
\hline & 2015 & 1 & 0 & 1 & 2 & 2 & 0 & 0 & 0 & 0 & 7 \\
\hline & 2016 & 0 & 1 & 0 & 6 & 6 & 3 & 1 & 0 & 3 & 5 \\
\hline & 2017 & 1 & 1 & 0 & 0 & 1 & 1 & 1 & 0 & 3 & 6 \\
\hline & 2018 & 0 & 0 & 4 & 3 & 0 & 4 & 1 & 1 & 2 & 5 \\
\hline & 2019 & 1 & 0 & 0 & 0 & 5 & 0 & 0 & 0 & 1 & 3 \\
\hline & 2020 & 0 & 0 & 0 & 0 & 0 & 0 & 0 & 0 & 1 & 0 \\
\hline \multirow{13}{*}{ Tocklai } & 2008 & 0 & 0 & 1 & 1 & 1 & 0 & 0 & 0 & 0 & 0 \\
\hline & 2009 & 2 & 1 & 0 & 1 & 1 & 1 & 0 & 1 & 0 & 0 \\
\hline & 2010 & 1 & 2 & 1 & 2 & 1 & 0 & 0 & 0 & 0 & 0 \\
\hline & 2011 & 1 & 1 & 0 & 3 & 2 & 1 & 1 & 0 & 1 & 0 \\
\hline & 2012 & 2 & 3 & 2 & 1 & 1 & 1 & 0 & 1 & 2 & 0 \\
\hline & 2013 & 0 & 2 & 0 & 3 & 3 & 1 & 1 & 0 & 0 & 0 \\
\hline & 2014 & 0 & 0 & 0 & 5 & 4 & 0 & 1 & 1 & 2 & 0 \\
\hline & 2015 & 1 & 3 & 0 & 4 & 3 & 1 & 3 & 0 & 1 & 0 \\
\hline & 2016 & 0 & 0 & 0 & 6 & 4 & 0 & 0 & 0 & 3 & 0 \\
\hline & 2017 & 0 & 0 & 1 & 9 & 7 & 0 & 1 & 0 & 3 & 2 \\
\hline & 2018 & 1 & 2 & 2 & 10 & 9 & 0 & 0 & 1 & 4 & 1 \\
\hline & 2019 & 0 & 1 & & 4 & 2 & 0 & 1 & 1 & 2 & 0 \\
\hline & 2020 & 0 & 1 & 3 & 0 & 5 & 0 & 0 & 0 & 3 & 0 \\
\hline
\end{tabular}

\section{References}

1. Yu, X.L., D.W. Sun, and Y. He, Emerging techniques for determining the quality and safety of tea products: A review. Comprehensive Reviews in Food Science and Food Safety, 2020. 19(5): p. 2613-2638. DOI: 10.1111/1541-4337.12611.

2. Ma, R., C. Ni, and J. Qiu, Scientific research competitiveness of world universities in computer science. Scientometrics, 2008. 76(2): p. 245-260. DOI: 10.1007/s11192-007-1913-7.

3. U.S. News \& World Report L.P. How U.S. News Calculated the Best Global Universities Rankings. New York 2020 2020.11.1; Available from: https://www.usnews.com/education/best-global-universities/articles/methodology .

4. Shanghai Ranking Consultancy. ShanghaiRanking's Global Ranking of Academic Subjects Methodology 2021. 2021; Available from: http://www.shanghairanking.com/methodology/gras/2021.

5. Zhao, R., Wang, S. et al., Evaluation and Analysis of Academic Competitiveness of the World-class University: 2014-2015. Journal of Chongqing University, 2015. 21(1): p. 24-29. DOI: 10.11835/j.issn.1008-5831.2015.01.015.

6. Zhao, R., Guo, F.J. et al., Evaluation and Analysis of Academic Competitiveness of the World-class University: 2015-2016. Evaluation E Management, 2015(3): p. 24-29.

7. Kong, Q., Tang, Y et al., Comparative Study on the Academic Competitiveness of Shandong Academy of Agricultural Sciences. Journal of Library and Information Sciences in Agriculture, 2018. 30(4): p. 56-68. DOI: 10.13998/j.cnki.issn1002-1248.2018.04.011.

8. Zhang, X., S. Mou, and N. Zhang, Research on the construction and practice of information service system of Universi ty Library from the perspective of "Double First Class". Journal of Library Science, 2018. 40(07): p. 49-54. DOI: 10.14037/j. cnki.tsgxk.2018.07.009.

9. Hirsch, J.E., An index to quantify an individual's scientific research output. Proceedings of the National Academy of Sciences of the United States of America, 2005. 102(46): p. 16569-16572. DOI: 10.1073/pnas.0507655102.

10. Molinari, J.F. and A. Molinari, A new methodology for ranking scientific institutions. Scientometrics, 2008. 75(1): p. 163-174. DOI: 10.1007/s11192-007-1853-2.

11. Clarivate. Essential Science Indicators. 2021; Available from: https://clarivate.com/products/essential-science-indicators/ .

12. Merigo, J.M., A.M. Gil-Lafuente, and R.R. Yager, An overview of fuzzy research with bibliometric indicators. Applied Soft Computing, 2015. 27: p. 420-433. DOI: 10.1016/j.asoc.2014.10.035. 
13. Kamdem, J.P., Duarte, A.E. et al., Research trends in food chemistry: A bibliometric review of its 40 years anniversary (19762016). Food Chemistry, 2019. 294: p. 448-457. DOI: 10.1016/j.foodchem.2019.05.021.

14. ParkJiyeon, 민윤경, and 김정 은, A Study on the Evaluation Methods of Research Institution: Based on the h-index and its Variants. Journal of the Korean Society for Information Management, 2010. 27(1): p. 249-267. DOI: 10.3743/KOSIM.2010.27.1.249.

15. Liu, M., Wang, T. et al., Chinese Institutions' Disciplinary Competitiveness in Crop Science Based on Bibliometrics. Agricultural Outlook, 2015. 11(03): p. 59-65.

16. Solanki, T., A. Uddin, and V.K. Singh, Research Competitiveness of Indian Institutes of Science Education and Research. Current Science, 2016. 110(3). DOI: 10.18520/cs/v110/i3/307-310.

17. Kim, J.-H., Noh, K.R. et al., Competitiveness Analysis of Institutes on Biomedical Magnesium Alloys. Asian Journal of Chemistry, 2014. 26(5): p. 1306-1308. DOI: 10.14233/ajchem.2014.17215.

18. Ruiz-Coronel, A., J.L. Jimenez-Andrade, and H. Carrillo-Calvet, National Cancer Institute scientific production scientometric analysis. Gaceta Medica De Mexico, 2020. 156(1): p. 4-10. DOI: 10.24875/gmm.M19000315.

19. Zhong, Y.Z., Ping, International Performance of Chinese Institutes in Different Disciplines --A Bibliometric View. journal of Intelligence, 2012. 31(04): p. 70-75.

20. Gundes, S. and G. Aydogan, Bibliometric analysis of research in international construction. Canadian Journal of Civil Engineering, 2016. 43(4): p. 304-311. DOI: 10.1139/cjce-2015-0127.

21. Trappey, A.J.C., Trappey, C.V. et al., A patent quality analysis for innovative technology and product development. Advanced Engineering Informatics, 2012. 26(1): p. 26-34. DOI: 10.1016/j.aei.2011.06.005.

22. He, W., Zhao, H.M. et al., Patent analysis provides insights into the history of cotton molecular breeding worldwide over the last 50 years. Journal of Integrative Agriculture, 2019. 18(3): p. 539-552. DOI: 10.1016/s2095-3119(18)62012-x.

23. Liu, Y., Fang, S et al., Research and Practice on Competitiveness Evaluation Model of Scientific Research Institutes Oriented to the Technological Field. Information studies: Theory \& Application. 2018. 41(10): p. 105-110. DOI: 10.16353/j.cnki.10007490.2018.10.017.

24. Wang, S., Qing, X.L. et al., Analysis of competitiveness of international geographic institutes based on bibliometrics. ACTA GEOGRAPHICA SINICA, 2017. 72(09): p. 1702-1716. DOI: 10.11821/dlxb201709014.

25. Clarivate. 2019 Journal Impact Factor, InCites Journal Citation Reports 2020.

26. The State Council of the People's Republic of China. National Medium and Long-term Science and Technology Development Plan (2006-2020). 2006; Available from: http://www.gov.cn/jrzg/2006-02/09/content_183787.htm .

27. The State Council of the People's Republic of China. Interpretation of Central No. 1 Document: Increasing investment in agricultural science and technology will become a new bright spot. 2012; Available from: http://www.gov.cn/jrzg/2012-02/08/content_2061349.htm .

28. China Economic Net. What is the connotation and significance of "precise poverty alleviation" mentioned by Xi Jinping. 2015; Available from: http://www.ce.cn/xwzx/gnsz/szyw/201508/04/t20150804_6121868.shtml .

29. The State Council of the People's Republic of China. The first report on the implementation of the rural revitalization strategy plan is released. The implementation of the rural revitalization strategy is off to a good start. 2020; Available from: http://www.gov.cn/xinwen/2020-06/09/content_5518147.htm . 